\title{
SCREENING OF THE T- AND B-CELL ANTIGENICITY IN NEONATAL CALVES OF THE HIS-TAGGED CRYPTOSPORIDIUM PARVUM ANTIGENS CP15, CP15/60, P23 AND TRAP-C1
}

\author{
Dirk C. de Graaf, Hans De Coninck, Cathérine De Clercq and Johan E. Peeters
}

Veterinary and Agrochemical Research Centre (VAR), Groeselenberg 99, B-1180 Brussels, Belgium

Cryptosporidium parvum Tyzzer, 1912 is the most commonly found enteropathogen during the first weeks of the life of calves, lambs and goat kids and is considered to be an important agent in the aetiology of the neonatal diarrhoea syndrome. Because of the limited availability of effective drugs, hygienic measures and good management are the most effective disease control measures (de Graaf D.C., Vanopdenbosch E., Ortega-Mora L.M., Abbassi H., Peeters J.E. 1999: Int. J. Parasitol. 29: 1269-1287). Immunoprophylactic control of Cryptosporidium infection is still under development and most studies focused on the passive transfer of colostral immunoglobulins from immunized dams to susceptible neonates, with sporozoite surface and microneme antigens being the target molecules of choice (de Graaf D.C., Spano F., Petry F., Sagodira S., Bonnin A. 1999: Int. J. Parasitol. 29: 1289-1306). Although the key position of $\mathrm{CD} 4{ }^{+} \mathrm{T}$-cell dependent interferon-gamma (IFN- $\gamma$ ) in acquired immunity against C. parvum (Ungar B.L., Kao T.C., Burris J.A., Finkelman F.D. 1991: J. Immunol. 147: 1014-1022) and C. muris (McDonald V., Robinson H.A., Kelly J.P., Bancroft G.J. 1994: Infect. Immun. 62: 2289-2294) is well documented, the development of a T-cell vaccine to be administered to the newborns themselves has so far received only little attention. In previous papers we described the specificity of the IFN- $\gamma$ response in the Cryptosporidium-infected bovine host (de Graaf D.C., Peeters J.E. 1997: Int. J. Parasitol. 27: 131-134) and the involvement of $\mathrm{CD}^{+} \mathrm{T}$-cells and a low molecular mass antigen preparation (de Graaf D.C., Walravens K., Godfroid J., Peeters J.E. 1998: Int. J. Parasitol. 28: 1875-1880). Further efforts to identify and purify a single parasite-derived antigen that evokes this immune response failed because of the limitations and constraints of the biochemical approach. Here we report the cloning of four known C. parvum surface or microneme antigens in a pBADTOPO-TA expression vector (Invitrogen, Carlsbad, CA, USA) and the evaluation of their $\mathrm{T}$ - and B-cell antigenicity in the bovine host.

Cryptosporidium parvum oocysts were purified from faeces of infected calves by biphasic diethyl ether/phosphate buffered saline (PBS) extraction and differential centrifugation on Percol. Sporozoites were liberated in prewarmed excystation fluid $\left(37^{\circ} \mathrm{C}\right)$ consisting of $0.75 \%(\mathrm{w} / \mathrm{v}$ in $\mathrm{PBS})$ sodium taurocholate with $0.25 \%$ bovine trypsine. Cryptosporidium sporozoite DNA was prepared according to a method optimized for the preparation of genomic DNA from bacteria (Ausubel F.M., Brent R., Kingston R.E., Moore D., Seidman J.G., Smith J.A., Struhl K. 1990: Current Protocols in Molecular Biology. Greene Publishing Associates, Brooklyn). PCR primers were designed for the amplification of the complete coding region (stop codon excluded) of the known C. parvum proteins CP15, CP15/60, P23 and TRAP$\mathrm{C} 1$ (see Table 1). Amplification was performed in a PerkinElmer model 9600 thermocycler by 30 cycles of denaturation at $94^{\circ} \mathrm{C}$ for $60 \mathrm{~s}$, annealing at $51^{\circ} \mathrm{C}$ for $60 \mathrm{~s}$ and extension at $72^{\circ} \mathrm{C}$ for $4 \mathrm{~min}$, with a supplementary annealing step at $72^{\circ} \mathrm{C}$ for 20 min after the last cycle to ensure that all PCR products were full length and 3' adenylated. The resulting amplicons had the expected lengths and were subsequently cloned in pBAD-TOPO-TA according to manufacturer's instructions. Cloning was confirmed by DNA sequence analyses of the retained pBAD-CP15, pBAD-CP15/60, pBAD-P23 and pBAD-TRAP-C1 clones. Indeed, we found a perfect match

Table 1. Genes retained for cloning in pBAD-TOPO-TA expression vector with their forward and reverse PCR-primers.

\begin{tabular}{|c|c|c|c|c|c|}
\hline Gene name & $\begin{array}{l}\text { GenBank }^{\mathrm{TM}} \\
\text { acc. No. }\end{array}$ & $\begin{array}{l}\text { Length } \\
\text { coding region } \\
\text { (stop codon } \\
\text { excluded) }\end{array}$ & $\begin{array}{l}\text { Primer } \\
\text { orientation }\end{array}$ & Primer sequence ( $5^{\prime}$ to $\left.3^{\prime}\right)$ & $\begin{array}{c}\text { Predicted } \\
\text { molecular weight } \\
\text { of the } \\
\text { corresponding } \\
\text { gene-product } *\end{array}$ \\
\hline CP15 & L34568 & $357 \mathrm{bp}$ & $\begin{array}{l}\text { forward } \\
\text { reverse }\end{array}$ & $\begin{array}{l}\text { ATGAAATTGGATGAGGTTGTT } \\
\text { CTTTAGAGGAATGAATCTGG }\end{array}$ & $13.3 \mathrm{kDa}$ \\
\hline CP15/60 & U22892 & $441 \mathrm{bp}$ & $\begin{array}{l}\text { forward } \\
\text { reverse }\end{array}$ & $\begin{array}{l}\text { ATGGGTAACTTGAAATCCTG } \\
\text { GTTAAAGTTTGGTTTGAATTTG }\end{array}$ & $16.2 \mathrm{kDa}$ \\
\hline P23 & U34390 & $333 \mathrm{bp}$ & $\begin{array}{l}\text { forward } \\
\text { reverse }\end{array}$ & $\begin{array}{l}\text { ATGGGTTGTTCATCATCAAA } \\
\text { GGCATCAGCTGGCTTGT }\end{array}$ & $11.2 \mathrm{kDa}$ \\
\hline TRAP-C1 & AF017267 & $2061 \mathrm{bp}$ & $\begin{array}{l}\text { forward } \\
\text { reverse }\end{array}$ & $\begin{array}{l}\text { ATGAAAAAGTTAATACTTTATTTAA } \\
\text { ACTAGCCCAGTTCTGACT }\end{array}$ & $76.0 \mathrm{kDa}$ \\
\hline
\end{tabular}

\footnotetext{
* Expression of the gene-products with a C-terminal tag will increase the size by approximately $2 \mathrm{kDa}$.
} 


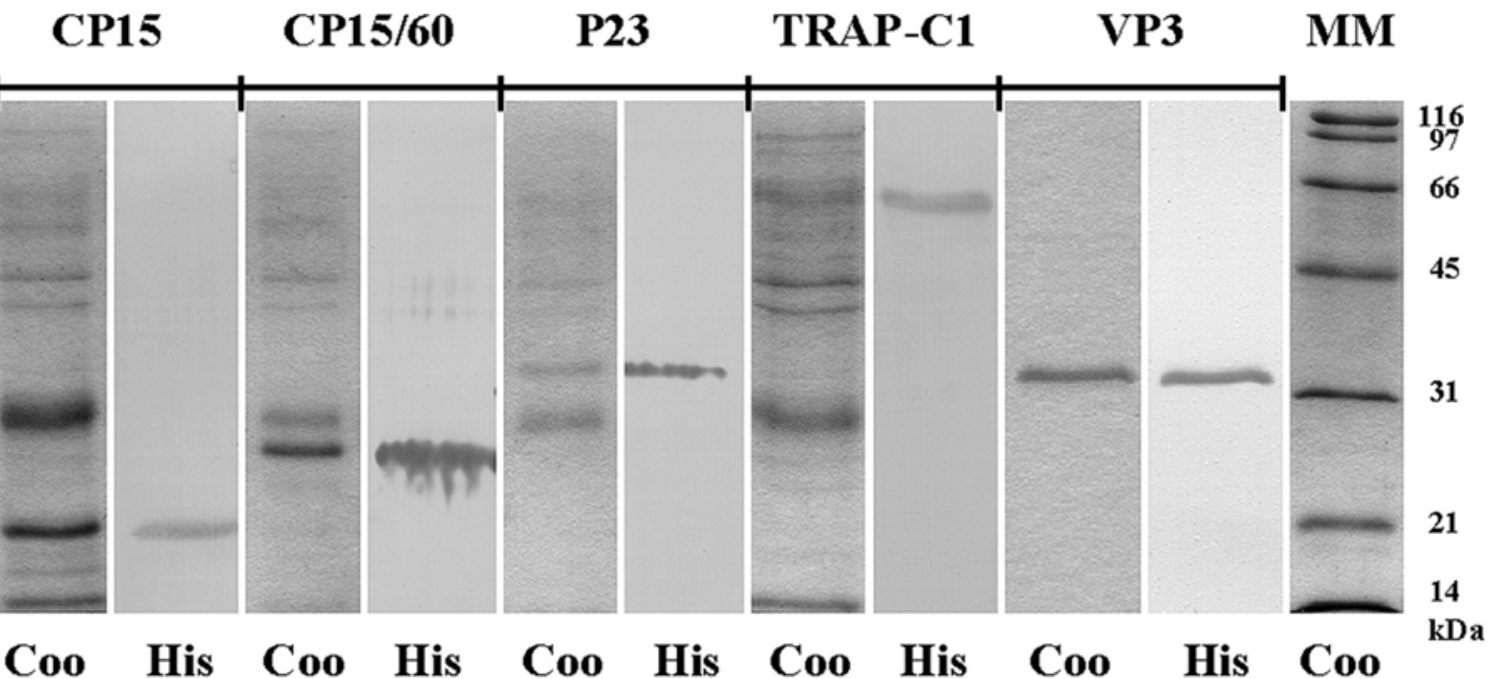

Fig. 1. SDS-PAGE of the partially purified His-tagged proteins CP15, CP15/60, P23, TRAP-C1 and VP3 stained with Coomassie Brilliant Blue (= Coo). The recombinant proteins were localised by an anti-His (C-terminal)-HRPO antibody (= His) on the flanking Westernblots. Contaminating bands were found in all Cryptosporidium parvum recombinant protein fractions, not in the VP3 fraction. (MM = Molecular mass markers)

with the published sequences $\left(\mathrm{GenBank}^{\mathrm{TM}}\right)$ of the corresponding genes for pBAD-CP15/60 and pBAD-P23, one silent mutation at position 318 ( $\mathrm{T}$ for $\mathrm{C}$ ) for pBAD-CP15 and 4 mutations (at position 431: $\mathrm{G}$ for $\mathrm{A}$; at position 912: $\mathrm{G}$ for $\mathrm{A}$; at position 1005: $\mathrm{T}$ for $\mathrm{C}$; at position 1218: $\mathrm{G}$ for $\mathrm{T}$; position numbering started at the beginning of the coding region) from which two silent mutations for pBAD-TRAP-C1. DNA sequencing was done by Eurogentec s.a. (Seraing, Belgium) according to the Single Run service, using the flanking pBAD-forward and reverse primers for only one primer extension in case of pBAD-CP15, pBAD-CP15/60 and pBAD-P23. Because of its length pBAD-TRAP-C1 was sequenced according to the Double Run service, meaning that new primers were designed to continue sequencing so that finally every basepair was read at least once in each orientation. Eurogentec s.a. used the ABI Prism BigDye Terminator Cycle Sequencing kit and the GeneAmp PCR system 9700, both from Applied Biosystem (Foster City, CA).

In the pBAD-TOPO-TA vector, expression of the cloned gene-product is turned on in the presence of L-arabinose. These recombinant gene-products contain a metal binding domain encoded by the polyhistidine tag, which allows purification by Immobilized Metal Affinity Chromatography on Invitrogen's ProBond ${ }^{\mathrm{TM}}$ Resin. For each purification cycle, fifteen $50-\mathrm{ml}$ cultures of one of the pBAD-clones were stimulated with L-arabinose (final concentration $0.2 \%$ ) at the mid-log phase and continued to grow for 4 more hours at $37^{\circ} \mathrm{C}$ with vigorous shaking. Cells were harvested by centrifugation $\left(3000 \mathrm{~g}, 15 \mathrm{~min}, 4^{\circ} \mathrm{C}\right)$, resuspended in Guanidinium Lysis Buffer ( $\mathrm{pH} 7.8$, Xpress ${ }^{\mathrm{TM}}$ System Protein Purification) and gently rocked to assure thorough cell lysis. After ultrasonication on ice and centrifugation, the lysate was transferred to a fresh tube. Column washing and elution occurred under denaturing conditions as described in the manufacturer's instruction manual. The purified His-tagged recombinant antigens were washed by 4 cycles of dilution in PBS with $0.5 \%$ Tween-20 (PBS/Tw) and concentrated on Vivaspin $2 \mathrm{ml}$ microconcentrators (cut-off: $10 \mathrm{kDa}$; Vivascience Ltd, Lincoln, UK). A pBAD-TOPO-TA clone encoding an irrelevant viral protein VP3, was kindly provided by Dr. G. Meulemans (VAR, Department of Small Stock Diseases, Brussels, Belgium). The corresponding His-tagged gene-product was purified by the same method as the recombinant Cryptosporidium antigens, and served as negative control. Purity was evaluated on a Coomassie Brilliant Blue stained SDS-PA-gel (Fig. 1). All samples except VP3 showed one major contaminating band of approximately $30 \mathrm{kDa}$ and some minor bands in the higher molecular mass region. Efforts to improve purification by additional washing steps only partially circumvented this problem. However, because the contaminants were the same in all the Cryptosporidium antigen preparations, mutual comparison of their antigenicity remained possible. Taken into account that expression in pBAD-TOPO-TA will increase the size of the gene-product with approximately $2 \mathrm{kDa}$ due to the C-terminal tag, the molecular weight of the purified recombinant proteins was in the expected range for CP15, CP15/60 and TRAP-C1. Recombinant P23 was found to have a molecular weight of more than double the predicted size based on the deduced amino acid sequence. The same observation was made by Perryman and colleagues (Perryman L.E., Jasmer D.P., Riggs M.W., Bohnet S.G., McGuire T.C., Arrowood M.J. 1996: Mol. Biochem. Parasitol. 80: 137-147) and might reflect the possible expression of P23 as a dimer.

Cellular immune recognition, more particularly the stimulation of a recall IFN- $\gamma$ response was tested on whole blood cultures. One $\mathrm{ml}$ heparinized blood samples from five Holstein bull calves that recovered from severe cryptosporidiosis were stimulated with $20 \mu \mathrm{l}$ purified recombinant antigen preparation (final concentrations $0.2,1.0$ and $5.0 \mu \mathrm{g} \mathrm{ml}^{-1}$ ). 


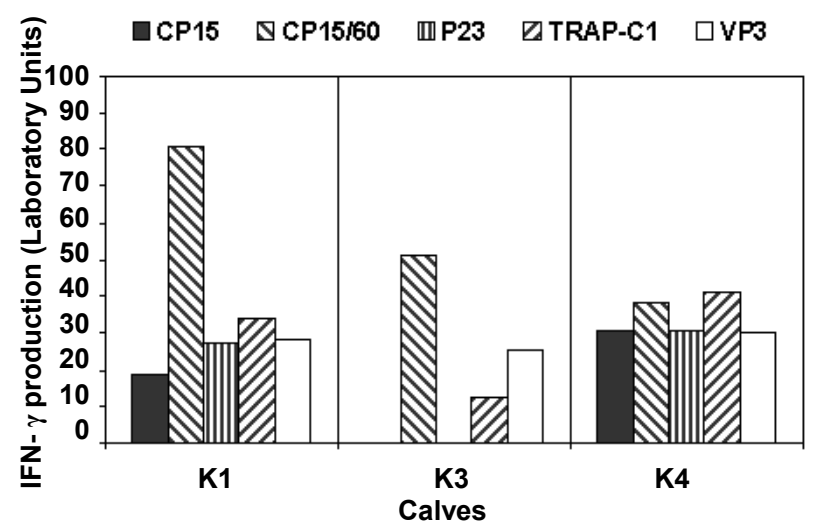

Fig. 2. IFN- $\gamma$ response to the different His-tagged Cryptosporidium parvum antigens. VP3 served as negative control. Only bovine whole blood cultures stimulated with CP15/60 gave an IFN- $\gamma$ production that was considerably higher than the negative control (calves K1 and K3).

Cryptosporidium parvum oocyst proteins extracted in PBS/Tw (adjusted to the same protein concentration) served as a positive control. Cultures were set up in duplicate and incubated for $24 \mathrm{~h}$ at $37^{\circ} \mathrm{C}$ in $95 \%$ air $-5 \% \mathrm{CO}_{2}$. After centrifugation $(260 \mathrm{~g}, 10 \mathrm{~min})$ the presence of IFN- $\gamma$ in plasma was determined by a commercial assay (BioSource Bovine IFN- $\gamma$ EASIA, BioSource Europe s.a., Nivelles, Belgium) as recommended by the manufacturer. An internal standard with a defined quantity of bovine IFN- $\gamma$ was introduced on each microplate at six dilutions in order to convert the optical densities into biological units by interpolation. From this internal standard the IFN- $\gamma$ dependent antiviral activity was measured by a microplate cytopathic effect inhibition assay using vesicular stomatitis virus and
Madin-Darley bovine kidney cells. One Laboratory Unit of bovine IFN- $\gamma$ was defined as the dilution at which there was $50 \%$ protection against virus induced lysis. This procedure failed to interpret IFN- $\gamma$ concentrations below 10 Laboratory Units. Best stimulation of the cellular immunity was obtained at $5 \mu \mathrm{g} \mathrm{ml}^{-1}$ antigen. Three calves (K1, K3 and K4) developed a recall IFN- $\gamma$ response against the parasite-derived antigen preparation (oocyst extract; data not shown). Two of them (K1 and K3) responded also against recombinant CP15/60 (Fig. 2). Cultures stimulated by the other C. parvum recombinant antigens showed a reactivity that was comparable to the back-ground response found in the negative control VP3. Thus, the stimulation in the former must be due to $\mathrm{CP} 15 / 60$ alone and not to the impurities present in all recombinant Crypto-sporidium antigen preparations.

Humoral antigenicity was tested against a pooled serum from five calves from a fattening unit that recovered from a Cryptosporidium infection. Pooled serum from five neonatal animals (aged between 8 and 10 days) that were kept free of infection by Halocur (Intervet Belgium) treatment served as negative control. Westernblots of the bacterial lysate of the different $\mathrm{pBAD}$ clones that expressed His-tagged Cryptosporidium antigens were stained with an anti-His (Cterminal)-HRP antibody to localise recombinant CP15, CP15/60, P23 and TRAP-C1 (Fig. 3). Using the pooled positive and negative bovine sera a complex band pattern of host-cell (E. coli) immuno-reactive antigens was visualised, but no antigenicity was seen at the expected gel migration altitude of the recombinant Cryptosporidium antigens (Fig. 3). The absence of immune-recognition of the three recombinant sporozoite surface proteins (CP15, CP15/60 and P23) by serum from Cryptosporidium-immune animals was unexpected, as the cloning of these antigens was at the time motivated by the immunodominant recognition of a 15 and 23 $\mathrm{kDa}$ antigen by serum and colostrum antibodies from $C$.
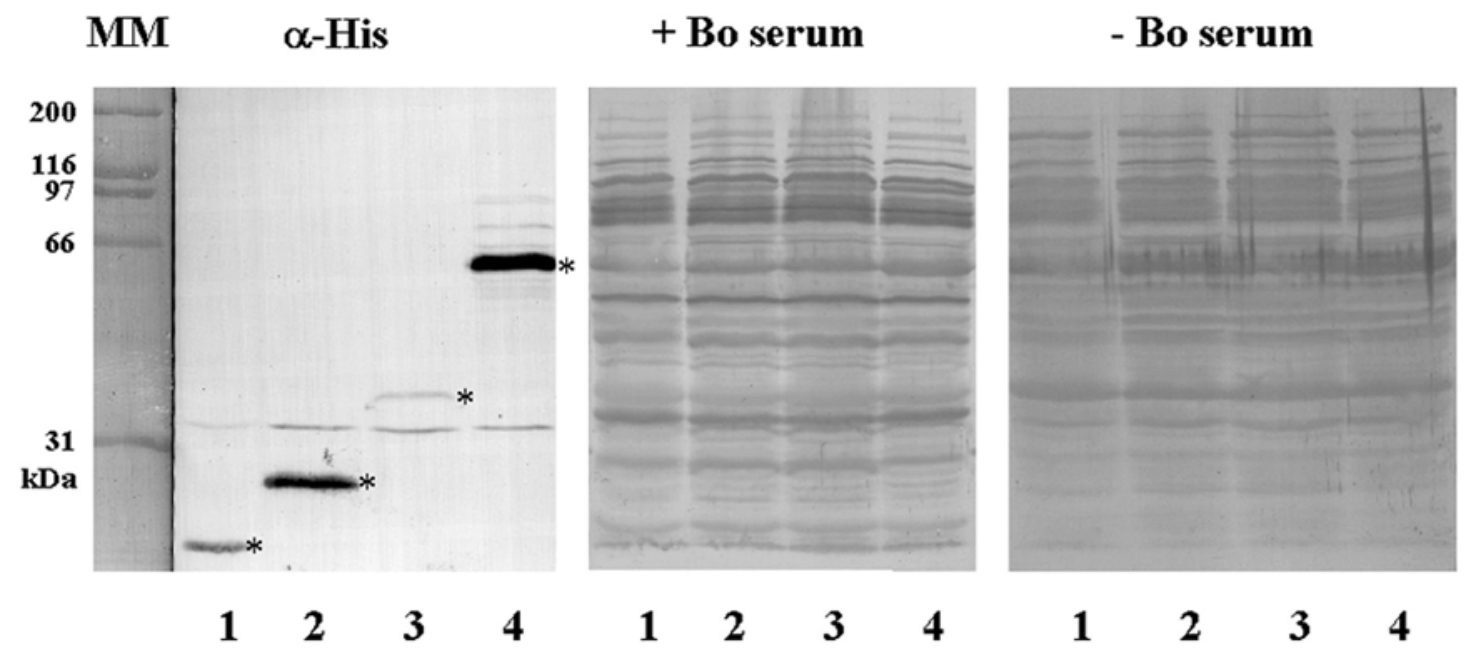

Fig. 3. Westernblot analysis of CP15 (lane 1), CP15/60 (lane 2), P23 (lane 3) and TRAP-C1 (lane 4) stained with a pooled serum from five calves that recovered from a Cryptosporidium infection (+ Bo serum) or a pooled serum from parasite-naive animals (Bo serum). There was no specific humoral recognition of any of the recombinant Cryptosporidium proteins. An anti-His (Cterminal)-HRPO antibody (= $\alpha$-His) served to localise the His-tagged proteins (marked by an asterisk). 
parvum-infected humans and animals (Reperant J.M., Naciri M., Iochmann S., Tilley M., Bout D.T. 1994: Vet. Parasitol. 55: 1-13). It might very well be that the recombinant Cryptosporidium antigens were not recognised by calf serum because they were expressed in a prokaryotic vector (pBAD) that fails to make the necessary secondary modifications on proteins from eukaryotic origin. Iochmann and colleagues (Iochmann S., Sagodira S., Mévélec M.N., Reperant J.M., Naciri M., Corsaget P., Bout D. 1999: Microb. Pathog. 26: 307-315) compared the antigenicity of two different recombinant forms of $\mathrm{CP} 15 / 60$, one produced in a prokaryotic expression system and the other in an eukaryotic one. The most potent immune response was obtained using the eukaryotic form, and according to the authors this was owing to post-translational modifications. Nevertheless, Wyatt and colleagues (Wyatt C.R., Brackett E.J., Mason P.H., Savidge J., Perryman L.E. 2000: Vet. Immunol. Immunopathol. 76: 309-317) found mucosal antibodies to P23 in calves with acute cryptosporidiosis. The target antigen used was likewise expressed in a prokaryotic vector (Perryman et al. 1996, op. cit.).

In conclusion: we have cloned four well-known Cryptosporidium antigens in a $\mathrm{pBAD}$ expression vector and found Tcell recognition of $\mathrm{CP} 15 / 60$ by the immune bovine host, but

Received 17 December 2001 no humoral recognition of any of the recombinant antigens. To our knowledge, this is the first report of a Cryptosporidium antigen that was proven to trigger a recall IFN- $\gamma$ response. Due to its subcellular localisation at the surface of the invasive sporozoite and merozoite stages, $\mathrm{CP} 15 / 60$ has so far only been applied in the development of antibody-based control strategies against cryptosporidiosis. Indeed, oral administration of anti-CP15/60 IgA mAb to suckling mice provided protection against infection (Tilley M., Upton S.J., Fayer R., Barta J.R., Chrisp C.E., Freed P.S., Blagburn B.L., Anderson B.C., Barnard S.M. 1991: Infect. Immun. 59: 10021007). And DNA vaccination of ewes with a plasmid encoding the CP15/60 protein mounted serum and colostral immunoglobulins levels (Jenkins M., Kerr D., Fayer R., Wall R. 1995: Vaccine 13: 1658-1664). Our observation that $\mathrm{CP} 15 / 60$ evokes a IFN- $\gamma$ response in sensitized animals opens new perspectives for this antigen, more particularly in the study of the cellular immune mechanisms against $C$. parvum and its possible application in the development of a T-cell vaccine.

Acknowledgement. This work was supported by a grant from the Belgian Ministry of Small Enterprises, Traders and Agriculture (Dienst Landbouwkundig Onderzoek; S-5840). 